\title{
Outlook for Vegetable Industry in China 2014-2023
}

\author{
Fantao KONG, Danhui LIANG, Chen SHEN, Shengwei WANG, Ke XU, and Lu XIONG \\ Agricultural Information Institute of Chinese Academy of Agricultural Sciences / Key Laboratory of Agri- \\ information Service Technology, Ministry of Agriculture, Beijing, China
}

\begin{abstract}
In the next decade, planting area of vegetable in China will slightly increase with an average annual growth rate of about $0.5 \%$. Vegetable production will reach 729.91 million tons in 2023 with an annual growth rate of about $0.8 \%$. Direct consumption of vegetables per capita will rise up to 166 kilogram in 2023 from 149 kilogram in 2013 with an average annual growth rate of about 1.1\%. The vegetable processing industry will develop rapidly, and vegetable processing demand will reach 173.27 million tons in 2023.

KEYWORD: Vegetable; Shopping basket program; Processing use; Loss rate; Technical barriers
\end{abstract}

Since the Reform and Opening, the vegetable industry in China has made great achievements. In 2013, vegetable planting area had reached 20 million hectares, the output value had reached 1.4 trillion yuan, the net export of vegetable had reached 9.4 billion tons, and the trade surplus had reached 11.1 billion dollars. Vegetable industry has become one of the important supporting industries of agriculture and rural economy. In the next 10 years, the scale of vegetable production will be stable due to factors of meteorological disasters, technical barriers and influence of uncertainty such as policies. The production in 2023 will be increased to around 730 million tons, and the vegetable net export will be reduced.

\section{BRIEF REVIEW OF THE VEGETABLE MARKET IN 2013}

\subsection{The planting area of vegetable had been expanded, the yield had increased}

From 2001 to 2012, the plating area of vegetable had increased rapidly to 3.95 million hectares except very few years' decrease. According to the information monitoring to the 580 key counties by Ministry of Agriculture, vegetables output in the field area in 2013 was slightly higher than before. Combining with the scientific and technological progress, vegetable yield had been further improved which promoted the vegetable production.

\subsection{Vegetable consumption had steadily increased}

In recent years, vegetable consumption of urban and rural households in China is slightly reduced.
However, with the increase of income, the outside home consumption was growing rapidly, coupled with the sustained growth of population, vegetable consumption in China presented a stability of increase overall. According to statistics, in 2012 China urban resident purchases of vegetable family per capita was 112.3 kilogram; and consumption of rural households per capita was 84.7 kilogram. The vegetable price kept growing, with obvious seasonal fluctuation

There was an obvious growing in vegetable price in 2013. As a result, the fresh vegetable price rose $8.1 \%$ from a year. The vegetable price fluctuation presented as a "V" glyph throughout the year [3]. During the Spring Festive, the price was relatively high in January and February and began to go down with a seasonal decline in March. It hit its lowest point in Jane; and a 3 month growing was found in the following third quarter, and in November and December, the price was stably increased.

\section{MARKET TREND ANALYSIS FOR THE NEXT DECADE}

\subsection{Production outlook}

\subsubsection{Plant area will keep expanding; growth speed will steadily slow down}

As an important economic crop, vegetable production still has higher comparative income comparing with other agricultural products. In recent years, the planting area of vegetable production expanded very fast, the average growth rate in the past 10 years was about $1.3 \%$ annually. In the future perspective period, the production of vegetable in China will still maintain its growth momentum. By 
2023, the planting area of vegetable will be increased to 20.57 million hectares, and the average growth rate will be $0.5 \%$. Among them, the expanding of vegetable planting area from 2014 to 2015 will be relatively fast, the growth rate will be about $1.4 \%$. However, with the constant expansion, the land resources for vegetable cultivation get limited. In addition, the impact of rising labor costs and population aging become unceasingly deepened. Thus, the growth of vegetable planting area will start to slow down. From 2015 to 2016, the growth rate of vegetable plating area will retard to $0.3 \%$, and the area will be stabilized at the level 20.53 million hectares after 2020.

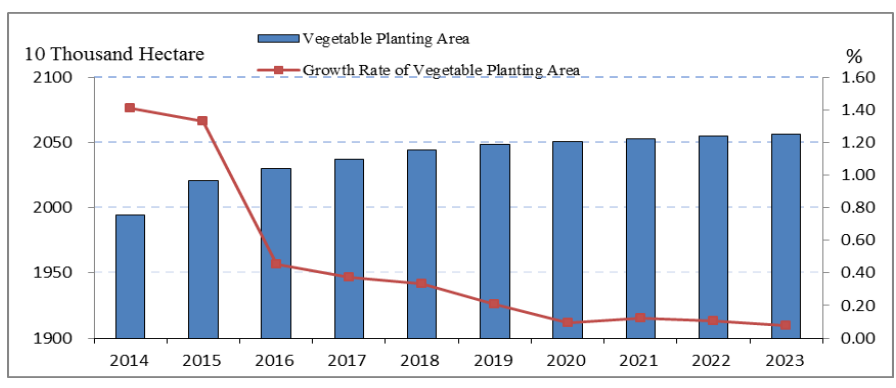

Fig. 1 Outlook for planting areas of vegetables in China during 2014-2023

\subsubsection{With the rapid development of protected vegetable and technology progress, the level of vegetable yield will continue improving}

In the future 10 years, the development of technology progress and protected vegetable will lead an increase in vegetable yield. Considering the development speed of protected vegetable is getting slower than it was in the past 10 years, the quality improvement of vegetable products is being paid by more attention, and the proportion of green vegetable and organic vegetable is becoming higher, the growth rate of vegetable yield will be significantly lower than $1.25 \%$ which is the average growth rate of the last 10 years. The yield will be increased from 34.5 tons per hectare in 2014 to 35.5 tons per hectare in 2023; the growth rate will remain at around $0.3 \%$ per year; and the cumulative increment will hit $3.0 \%$. In terms of absolute value, the vegetable yield will have an increase of 10.9 kilogram annually from 2014 to 2015, and after 2017 , the increase of yield will be decreased to 5.4 kilogram (Fig. 2).

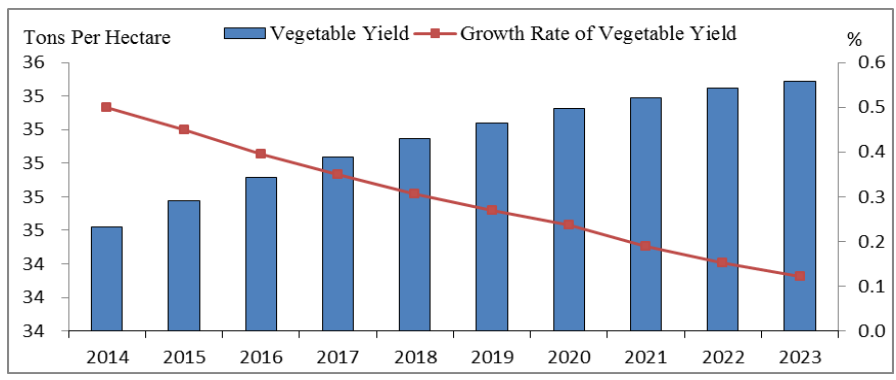

Fig. 2 Outlook for vegetable yield in China during 2014-2023

\subsubsection{Affected by the growth of scale and yield, vegetable production will keep increasing}

Affected by the increasing planting area and yield of vegetable, the production of vegetable is expected to increase as well. By 2023, the production of vegetable will reach about 7.3 billion tons. Moreover, since the increase of planting area and yield are relatively fast from 2014 to 2015, the growth of production will remain at about $1.9 \%$ which is relatively fast as well. However, with the slackened growth speed of planting area and yield, the production will also be slowing down. The average growth rate will be decreased to $0.6 \%$ from 2016 to 2019. After, 2020, it will be further reduced to about $0.3 \%$ (Fig. 3).

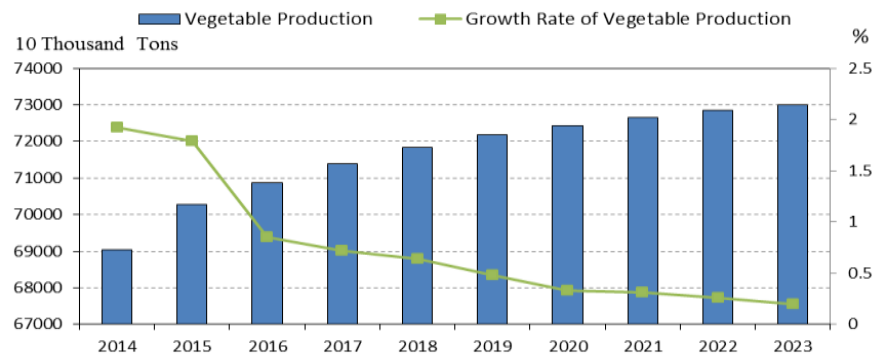

Fig. 3 Outlook for vegetable production in China during 20142023

\subsection{Consumption Outlook}

10 years in the future, the consumption of vegetable will keep increasing. Meanwhile, direct consumption for residents increases slowly, processing use increases fast, feed consumption basically remains unchanged, and loss becomes less. Based on the comprehensive situation of direct consumption, processing use, feed consumption, and loss, the consumption of vegetable in China will be increased to 7.2 billion tons with an annual growth rate of $0.8 \%$, which is slightly greater than the growth of vegetable production.

\subsubsection{Direct consumption of vegetable will increase gradually, especially of rural residents per capita}

When the National Bureau of Statistics calculates the consumption of vegetable per capita, outside consumption is not included in it. However, the outlook research does consider about the quantity of outside consumption. The outside home consumption costs and food consumption cost of urban residents from National Bureau of Statistics showed that the proportion of outside consumption expenditure had increased year by year from $14.7 \%$ in 2000 to 21.8 in 2012 . In the next 10 years, with the increasing income, residents will pay more attention on health and dietary nutrition balance. At present, vegetable consumption of rural residents could still be further to rise. The growth rate of 
vegetable consumption per capital of rural residents will boost more significantly as compared to urban residents. From 2014 to 2023, growth rate of vegetable consumption per capita of rural residents will remain at $1.9 \%$ annually, from 130 kilogram per year in 2013 to 157 kilogram per year in 2023. In 2013, vegetable consumption per capita of urban residents already reached 166 kilogram per year. In the future, vegetable consumption per capita of urban residents grows slowly with an annual growth rate of $0.3 \%$. By 2023, vegetable consumption per capita of urban residents will reach 171 kilogram per year, and the gap between urban and rural area will be further narrowed. Vegetable consumption per capita in China will gain to 166 kilogram per year in 2023 from 149 kilogram per year in 2013 with an annual growth rate of about $1.1 \%$ (Fig. 4).

Along with the increase of population and urbanization level, the quantity of direct consumption is expected to reach 236.26 million tons with an annual growth rate of $1.5 \%$. Moreover, before 2020, vegetable consumption per capita and population increase fast, the direct consumption will increase fast as well with an annual growth rate of $1.6 \%$. After 2020, the direct consumption will slow down smoothly with an annual growth rate of $1.3 \%$.

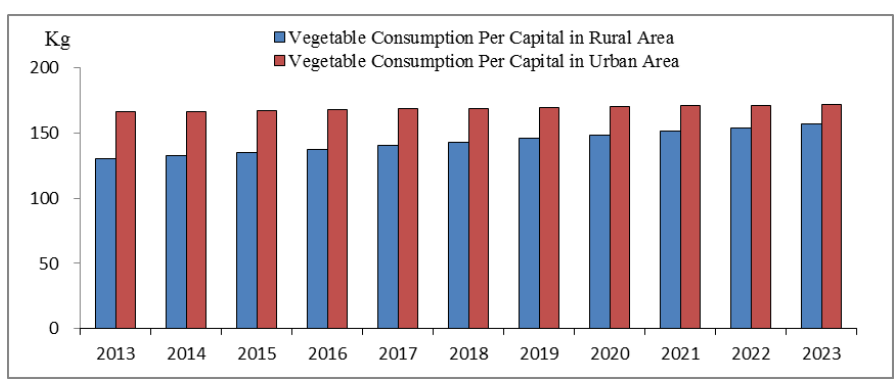

Fig. 4 Outlook for direct consumption of vegetable per capita in China during 2014-2023

\subsubsection{Rapid increase in the use of vegetable processing}

In 2009, the number of vegetable processing enterprises with designated size in China had been more than 10 thousands, and the production of the year was 45 million tons with a 92 million tons consumption of raw vegetables, and the processing rate had come to $14.9 \%$ [2]. In pace with the developing economy and urbanization level, the demand for processed vegetable is markedly increased for hectic life. In the next 10 years, consumer demand for processed vegetable will increase rapidly. By 2023, the use of China vegetable processing will be up to 173.27 million tons; and the average increment will be around 3.78 million tons. In the prospective period, the average growth rate of vegetable processing use will remain at $2.5 \%$ per year, and the cumulative increment will be $27.9 \%$. The proportion of vegetable processing in the industry will approach to $24 \%$ by the end of 2023 (Fig. 5).

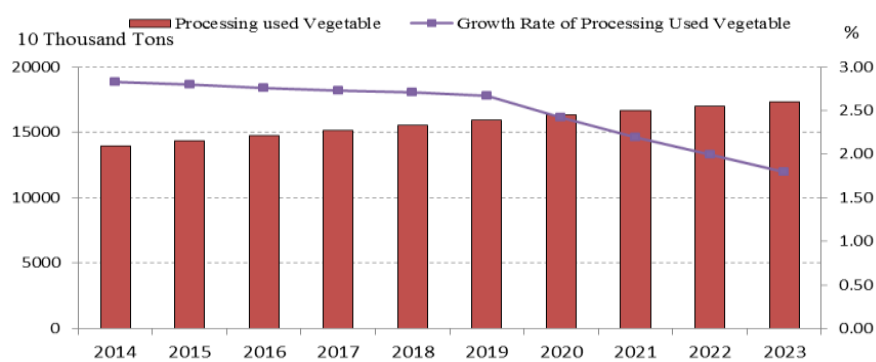

Fig.5 Outlook for processing used vegetable in China during 2014-2023

\subsubsection{Feed consumption of vegetable will be stable; and the loss rate will fall}

Only a small part of vegetable will be used as feed. According to FAO, the feed consumption of vegetable in China was only 29.56 million tons in 2009. In the research, the feed consumption of vegetable in 2013 is set to be 30 million tons, which is about $5 \%$ of the vegetable production. And it is expected to get 37.24 million tons by the end of 2023 with an annual growth rate of less than $1 \%$.

Vegetable has the characters of high moisture, perishable, bad storage stability, and high loss rate in harvest, processing, storage, preservation, and transportation. According to the estimates of relevant department, rot damage rate during vegetable circulation is about $20 \%$ to $30 \%$ [2]. Considering about other losses, the vegetable loss rate should be approximately $30 \%$ to $50 \%$ [2]. In this study, we assume that the rate was $35 \%$ in 2013 . Taking into account the development of storage facilities and the construction of cold chain system, in the next 10 years, the loss rate of vegetable will gradually reduce with an annual decrement of $0.9 \%$. By 2023, the loss rate of vegetable will be $5.4 \%$ less than it was in the base year.

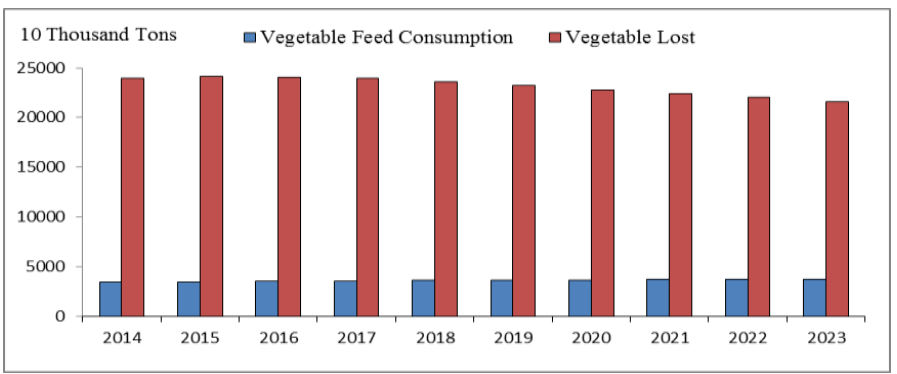

Fig. 6 Outlook for feed consumption and loss of vegetable in China during 2014-2023

\section{THE MAIN PROBLEMS AND UNCERTAINTIES}

\subsection{Quality and safety factors}

The level of vegetable quality will directly lead a stabilized vegetable production and safe consumption. In China, the quality of vegetable is safe and assured to eat as a whole. However, pesticide residues which exceed the standards occur 
in some particular species locally. Following by the exposure of pesticide residues on cowpea and leek in 2010, "poisoned ginger" was reported in Weifang, Shandong, 2013. It not only caused a panic in consumption, but also brought a huge damage to the main producing area. Looking into the future, if the quality and safety of vegetable could not be guaranteed, the production of vegetable would be hurt, even to the peasants' income.

In 2014, the Government Work Report indicated that the government would resolutely governance the problem of pollution on table and practically protect "the safety on the tip of tongue" using the most stringent regulation, the severest punishment, the most serious accountability system. "National Vegetable Industry Development Plan (2011-2020)" also specified that vegetable production should meet the National Agricultural Production Safety Standards and the National Food Safety Standards. Vegetable commercial processing rate should be increased to $50 \%$ in 2015 , and to $60 \%$ by the end of 2020 . In the future, the level of vegetable quality and safety in China would be greatly improved by the smooth construction progress of standard vegetable gardens and demonstration counties (areas) of agricultural standardization, gradual consummation of quality and safety controlling systems, preliminary establishment of quality and safety traceability system, effective implement of "Food Safety Law" and "Quality and Safety Law of Agricultural Products".

\subsection{Policy factors}

Based on the long-term implementation of "Shopping Basket" program and responsibility held directly by mayors, the Ministry of Agriculture issued the "New Guiding and Planning for the construction of 'Shopping Basket' Program" to further strengthen the support to the work of vegetable. Meanwhile, all regions had obtained certain effects by actively using the stabilization fund for price to regulate the vegetable market. The stability of the policy would ensure the stable development of vegetable production.

As to the frequent problem of volatile price and unsalable vegetable, the Chinese government is actively exploring and constructing long-acting mechanism for price stability [1][7]. Many cities have positively launched the pilot of vegetable price insurance in order to reduce price volatility and the risk of vegetable production and operation. In the future, the implementation and extension of vegetable regulation directory and relative policies will play a positive role in stabilizing the vegetable production supply and guaranteeing the producers' income.

\subsection{Trade factors}

The future external environment of China vegetable trade is becoming more complex which has distinct effects to the export and import. The first one is the comparative advantage of vegetable is going to be weakened. Affected by the sharp rise on vegetable production and processing costs, the profit space of vegetable export enterprises will start to be narrowed. The second one is the uncertainties in Free Trade Agreement (FTA) negotiations. The third one is the tax rebate of national export varies unpredictably which brings direct impacts to vegetable trade. Since March $1^{\text {st }}, 2012$, the State Administration of Taxation cancelled the series tax rebates for vegetable and vegetable processing (including deep processing), vegetable export enterprises have been affected to a certain degree [5]. Looking into the future, changes of export tax rebate will directly affect to the increase and decrease of vegetable export. The fourth one is the rigorous technical barrier to trade that vegetable export has to face. In recent years, some target countries and regions importing vegetable have highlighted the quality of imported vegetable.

\section{REFERENCES}

[1] Chen, YF. \& Ma, GY. 2012. Evaluation and Inspiration of Vegetable Price Stabilization Mechanism in Japan. Japanese Studies 1: 65-77.

[2] National Development and Reform Commission, Ministry of Agricultural. 2012 National Vegetable Industry Development Plan (2011-2020).

[3] Kong, FT. Zhang, YM. Wang, DJ. \& Li, HS. 2013. Annual Report of Vegetable Market Situation Analysis in 2013.

[4] Leng, Y. Wang, JJ. \& Zhang, ZH. 2012 A Decade in WTO, Comparative Analysis of China Vegetable Import and Export. China Vegetables 17: 1-7.

[5] Li, CG. Zhang, SY. \& Xiao, XY. 2013. Situation and Issues of China Vegetable Export Trade in 2012. China Vegetables 11: 1-4.

[6] Liu, JF. Qi, CJ. \& Zhao, Y. 2009. Newest Situation Analysis of China Vegetable Export. China Vegetables 3: 4-5.

[7] $\mathrm{Mu}, \mathrm{YY}$. 2012. Discussion on Vegetable Production Subsidy Policies - From the View of Vegetable Price. China Vegetables 19: 1-7.

[8] Zhang, XF. Yue, SM. 2008. SWOT Analysis and Export Orientation of China Vegetable Industry. Shandong Economy 1: 152-156. 